\title{
A Synergistic Acceleration of Corrosion of Q235 Carbon Steel Between Magnetization and Extracellular Polymeric Substances
}

\author{
Hong-Wei Liu ${ }^{1}$ - Da-Ke Xu ${ }^{2}$ - Bi-Juan Zheng ${ }^{1} \cdot$ Muhammad Asif $^{1} \cdot$ Fu-Ping Xiong ${ }^{1}$ Guo-An Zhang ${ }^{1}$. \\ Hong-Fang Liu ${ }^{1}$
}

Received: 9 June 2017/Revised: 24 July 2017/Published online: 16 October 2017

(C) The Chinese Society for Metals and Springer-Verlag GmbH Germany 2017

\begin{abstract}
In this work, surface characterization and electrochemical measurement were employed to investigate the effects of magnetic field (MF) on the corrosion of Q235 carbon steel in a $\mathrm{NaCl}$ solution containing sulphate-reducing bacteria (SRB) or extracellular polymeric substances (EPS). Results demonstrated that a $150 \mathrm{mT}$ MF enhanced steel corrosion in a SRB-containing $\mathrm{NaCl}$ solution by $202 \%$ calculated from weight loss with pitting corrosion as the main corrosion type. Either EPS or MF rendered steel corrosion, but a synergistic interaction between MF and EPS boosted up steel corrosion. This synergistic enhancement could be referred to the alteration in orientation of EPS induced by MF. The presence of higher percentage of chloride ions on the carbon steel surface manifested that MF initiated the erosion of chloride ions on the carbon steel coupon.
\end{abstract}

KEY WORDS: Sulphate-reducing bacteria; Magnetic field; Extracellular polymeric substances; Microbiologically influenced corrosion

\section{Introduction}

Microbiologically influenced corrosion (MIC) can be found in various environments including freshwater, seawater and petroleum chemical engineering [1-4]. It is estimated that $20-30 \%$ of corrosion damage is triggered by MIC, in which

Available online at http://link.springer.com/journal/40195

Da-Ke Xu

xudake@imr.ac.cn

$\triangle$ Hong-Fang Liu

liuhf@hust.edu.cn

1 Key Laboratory for Large-Format Battery Materials and System, Ministry of Education, School of Chemistry and Chemical Engineering, Huazhong University of Science and Technology, Wuhan 430074, China

2 Institute of Metal Research, Chinese Academy of Sciences, Shenyang 110016, China sulphate-reducing bacteria (SRB) are blamed as the chief culprits [5-7]. SRB consumes sulphate as an electron acceptor for the utilization of organic compounds and produces sulphide $[8,9]$. They can tolerate comparatively wide range of temperatures, $\mathrm{pH}$ values, chlorides and hexavalent chromium concentrations [10].

Extracellular polymeric substances (EPS) including polysaccharides, proteins, nucleic acids, lipids and other biological molecules $[11,12]$ play as the key constituents for the aggregation of microorganisms [13]. EPS, an extremely hydrated gel matrix, can encourage microbial cells to form stable and synergistic consortia and shield biofilm against biocides [14, 15]. Cathodic reduction of oxygen could be retarded by the adsorbed EPS film secreted by SRB [16], protecting the metal substrate from corrosion [17].

Recently, magnetic fields (MF) were employed as an innovated technique for biological wastewater treatment [18-20]. However, the MF engendered by industrial 
electromagnetic tools or provoked by magnetically water treatment would also control metal corrosion [21-25]. The MF can change the mass transfer rate by a convective force in an electrochemical system. This force $(F)$ is given by:

$F=q(V \times B)$,

where $q$ is the charge $(C)$ on the species; $V$ is the velocity $\left(\mathrm{m} \mathrm{s}^{-1}\right)$; and $B$ is the magnetic field intensity $(T)$. A local convection flow of the solution is owing to the momentum transfer between the moving species and the solvents [26]. This phenomenon satisfies the magnetohydrodynamic force (FMHD), which is given by:

$\mathrm{FMHD}=J \times B$,

where $J$ is the local flux of ions. The orientation of MF determines the mass transfer rate with respect to the ion flux. Thus, a Lorentz force, and then a MHD velocity, will be applied to any charged particle moving in the interfacial layer [26].

The MF can inhibit many types of microbes [27-30]. The amounts of bacteria cells and their viability decrease with an increased MF exposure time, elevated temperatures and higher MF intensities. Furthermore, the population of planktonic SRB decreased by $15 \%$ in an extremely lowfrequency magnetic field for short exposure [28].

Our previous work found that a low-intensity MF of 4 $\mathrm{mT}$ could delay the formation of SRB biofilm and inhibited the corrosion of 304 stainless steel [31]. However, Bahaj et al. [32] demonstrated that a moderate intensity MF of $150 \mathrm{mT}$ enhanced the corrosion rate of pure iron in the presence of SRB. They concluded that the increase of corrosion rate in both cases was due to the upsurge of bacterial adhesion and the prompt production of an anaerobic environment, a result of the synergistic interaction between MF and SRB. Al-Abbas et al. [26] similarly revealed that a $300 \mathrm{mT}$ MF stimulated biofilm formation and enriched corrosion of pipeline steel caused by SRB.

Based on the significance of EPS in the bacteria attachment and biocorrosion, we further investigated the effects of synergistic interaction between magnetization and EPS secreted by SRB. The objective was to figure out the contribution of MF and EPS to steel corrosion when MF was used to control MIC.

\section{Experimental}

Q235 carbon steel was used for corrosion coupons with the chemical composition (wt \%) of C 0.3, Si 0.01, Mn 0.42, S $0.029, \mathrm{P} 0.01$ and Fe balance. The working electrodes with a diameter of $15 \mathrm{~mm}$ and a thickness of $2 \mathrm{~mm}$ were used for electrochemical measurements. To measure weight loss, coupons with the size of $50 \mathrm{~mm} \times 13 \mathrm{~mm} \times 1.5 \mathrm{~mm}$ were prepared. All the coupons were abraded with a series of $\mathrm{SiC}$ waterproof abrasive papers $(600,1000$ and 1200) followed by metallographic abrasive paper. After abrasion, these coupons were washed and degreased in ethanol and distilled water, respectively. All coupons were finally dried using nitrogen gas.

SRB were isolated from the sludge in Sinopec oilfield (Shandong province, China) and have already been identified in a previous report [33]. API-RP38 culture medium was used, and the corresponding composition was $\left(\mathrm{g} \mathrm{L}^{-1}\right)$ : $\mathrm{K}_{2} \mathrm{HPO}_{4} 0.01, \mathrm{MgSO}_{4} \cdot 7 \mathrm{H}_{2} \mathrm{O} 0.2,(\mathrm{NH})_{2} \mathrm{Fe}\left(\mathrm{SO}_{4}\right)_{2} 0.2, \mathrm{NaCl}$ 10 , yeast extract 1.0 , vitamin $\mathrm{C} 0.1$, in addition to $4.0 \mathrm{ml}$ $\mathrm{L}^{-1}$ sodium lactate $(\mathrm{pH}$ 7.2). Before inoculation, $\mathrm{SRB}$ culture medium was autoclaved at $121{ }^{\circ} \mathrm{C}$ for $20 \mathrm{~min}$. SRB were incubated at $37{ }^{\circ} \mathrm{C}$.

The extraction of EPS was achieved according to the method described by the previous report [34]. After 10 days of incubation, SRB culture medium was centrifuged at $14,000 \mathrm{rpm}$ for $20 \mathrm{~min}$. The supernatant was concentrated to $200 \mathrm{~mL}$ in an $80^{\circ} \mathrm{C}$ water bath and then filtered using a sterile $0.22 \mu \mathrm{m}$ membrane to separate microbial cells. The obtained EPS was preserved in a frozen state. UV-visible spectrophotometer (CARY 50 Scan, VARIAN) and an attenuated total reflection infrared (ATR-IR) spectroscope (VERTEX 70, Bruker) were used to analyse the composition of EPS.

An optical microscope (OM, VHX-1000, KEYENCE) was used to investigate the corrosion morphology (after removing the corrosion products) of Q235 carbon steel after 8 days of incubation in a $3 \mathrm{wt} \% \mathrm{NaCl}$ solution in the presence of SRB. Furthermore, the carbon steel surfaces were observed using a scanning electron microscope (SEM, Sirion200, FEI). The corrosion products were analysed using an energy dispersive $\mathrm{X}$-ray detector.

The schematic illustration for electrochemical measurements is presented in Fig. 1. Electrochemical workstation (CHI660C, Chenhua) was used for all

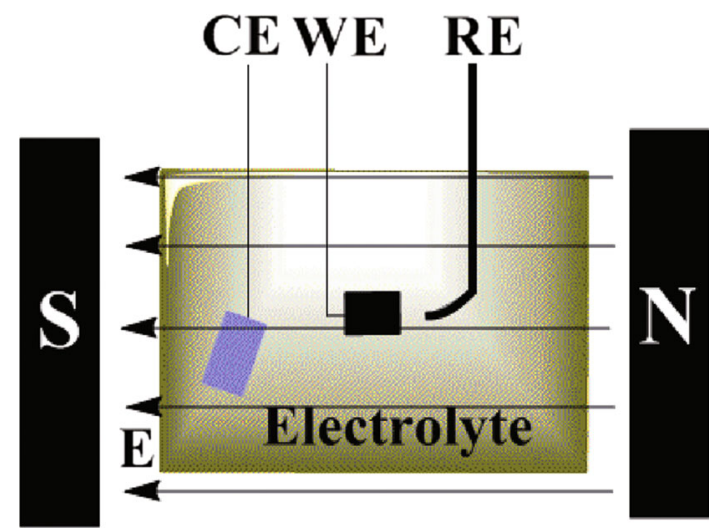

Fig. 1 Schematic diagram of set-up for electrochemical measurements with MF 
electrochemical measurements along with Pt electrode and saturated calomel electrode (SCE) as the counter electrode and reference electrode, respectively. For the group in the presence of $\mathrm{SRB}$, the $3 \mathrm{wt} \% \mathrm{NaCl}$ solution consisting of $10 \%$ culture medium was used as electrolyte. For the group with EPS, the Q235 working electrodes immersed in a 3 wt\% $\mathrm{NaCl}$ solution with 5\% EPS to guarantee the adsorption equilibrium with EPS for $1 \mathrm{~h}$ before electrochemical tests. Then electrochemical measurement was executed in the $3 \mathrm{wt} \% \mathrm{NaCl}$ solution only. The MF intensity employed was $150 \mathrm{mT}$. The perturbations in the frequency range from $100 \mathrm{kHz}$ to $10 \mathrm{mHz}$ at open-circuit potential (OCP) with $10 \mathrm{mV}$ sinusoidal was used to perform electrochemical impedance spectroscopy (EIS). The polarization curves were conducted between $+200 \mathrm{mV}$ (vs. OCP) and $-200 \mathrm{mV}$ (vs. OCP) at a scan rate of $0.5 \mathrm{mV} \mathrm{s}^{-1}$. The cyclic double-polarization measurements were measured in the range of -1.5 to $0.1 \mathrm{~V}$ (vs. OCP) at a scan rate of $0.5 \mathrm{mV} \mathrm{s}^{-1}$. The starting point of the potential sweep was established in the cathodic region of the $E-i$ ( $E$ and $i$ represent the potential and current density, respectively) data, which was liable to minimize the oxidation reaction of iron at the electrode surface. All the data were analysed by Zview2 and Cview2 software. Each test was performed in triplicate.

\section{Results and Discussion}

\subsection{Steel Corrosion in an SRB-Containing Solution}

\subsubsection{Weight Loss and Morphology}

Weight loss of coupons after 8 days of inoculation in the presence of $\mathrm{SRB}$ with and without $\mathrm{MF}$ in $3 \mathrm{wt} \% \mathrm{NaCl}$ solution is presented in Table 1. In this work, the coupon without MF was as control. Compared with the control, the weight loss has increased by $202 \%$ under the MF of 150 $\mathrm{mT}$, demonstrating that the MF extraordinarily accelerated steel corrosion in the presence of SRB. Figure 2 illustrates the corrosion morphologies of the coupon surfaces after removing biofilm. Pitting corrosion was the major corrosion type in the presence of SRB. Moreover, the number of corrosion pits per unit area and average size of the corrosion pits measured are shown in Table 1. With the assistance of MF, not only the number of the pits on steel surface increased remarkably, but the sizes of the corresponding pits became considerably larger. MF with higher intensity of $50 \mathrm{mT}$ was helpful to accelerate SRB corrosion. These results were in good agreement with the measurement results of weight loss. SRB is capable of promoting localized corrosion [35]. This is mainly due to the heterogeneous SRB biofilm [36], and SRB can obtain electrons from $\mathrm{Fe}^{0}$ directly [37], resulting in pitting corrosion [4]. MF can influence SRB activity and the migration of corrosive ions [31, 38], which can be one of the important reasons that MF with the intensity of $50 \mathrm{mT}$ can promote SRB corrosion.

\subsubsection{Electrochemical Measurements}

The polarization curves of Q235 carbon steel in a $3 \mathrm{wt} \%$ $\mathrm{NaCl}$ solution in the presence of SRB after 8 days of incubation are shown in Fig. 3, and the corresponding fitted results are listed in Table 2 . It showed that the corrosion current density $\left(i_{\text {corr }}\right)$ was larger than that without $\mathrm{MF}$ (Table 2), indicating that MF could promote SRB corrosion. The substantial change of $b_{\mathrm{c}}\left(b_{\mathrm{c}}\right.$ represents the cathodic Tafel slope) indicated that MF seriously influenced the rate of cathodic reduction process. In this neutral system, paramagnetism oxygen can easily migrate to the steel surface in the presence of MF [38], thus resulting in more consumption of oxygen. Then, the cathodic reaction will be promoted, leading to a higher cathodic current density. Therefore, MF undoubtedly changed the process of oxygen reduction or the diffusion of dissolved oxygen, which also has been verified in a previous report [38].

Figure 4 illustrates Nyquist plots with SRB in the absence and presence of MF after 8 days of incubation. The EIS data were fitted by the equivalent circuit, as shown in Fig. 5, where the parallel $R_{\mathrm{ct}}$ and $C_{\mathrm{dl}}$ denote the impedance of the double layer and the double layer capacitance, and the parallel $R_{\mathrm{f}}$ and $C_{\mathrm{f}}$ correspond to the impedance of the SRB biofilms and the capacitance of the biofilm. The corresponding fitted results of $R_{\mathrm{ct}}$ values are shown in Table 3. The $R_{\mathrm{ct}}$ values are closely related to the steel corrosion. The lower $R_{\mathrm{ct}}$ values can lead to higher steel corrosion rates [39]. The smaller $R_{\mathrm{ct}}$ values under MF of $150 \mathrm{mT}$ indicated a higher corrosion rate, confirming that

Table 1 Weight loss of Q235 carbon steels after 8 days of incubation in the presence of SRB with and without $\mathrm{MF}$ in $3 \mathrm{wt} \% \mathrm{NaCl}$ solution

\begin{tabular}{llcr}
\hline MF $(\mathrm{mT})$ & Average mass loss $\left(\mathrm{g} \mathrm{cm}^{-2}\right)$ & Average size $(\mu \mathrm{m})$ & Number of pits $\left(\mathrm{pit} \mathrm{mm}^{-2}\right)$ \\
\hline 0 & 0.0213 & $6 \pm 2$ & $50 \pm 10$ \\
150 & 0.0431 & $30 \pm 10$ & $550 \pm 50$ \\
\hline
\end{tabular}



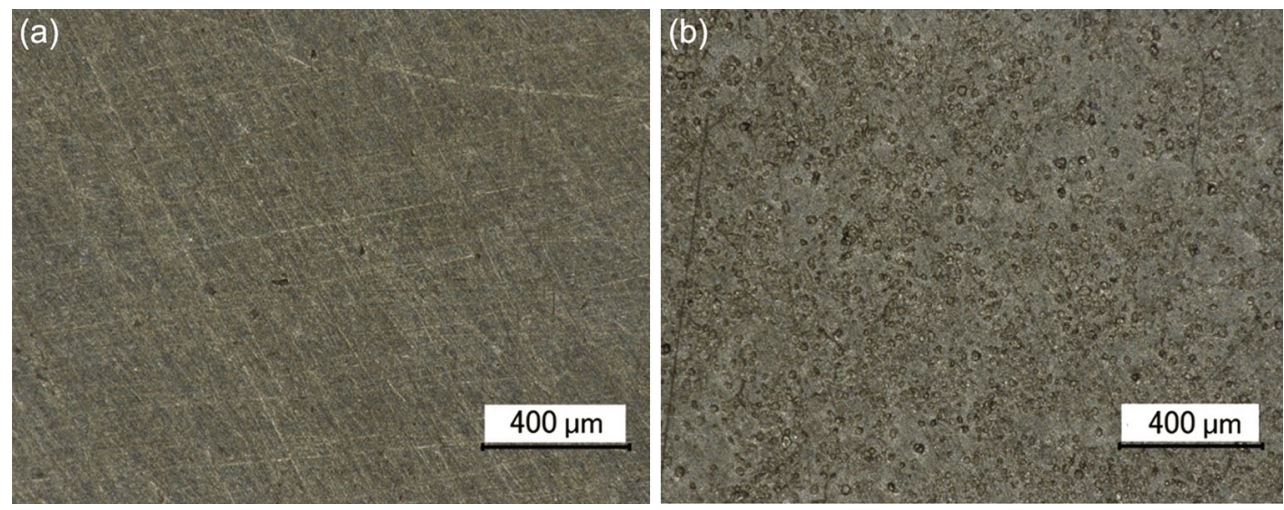

Fig. 2 Images of coupons surface after exposure to $3 \mathrm{wt} \% \mathrm{NaCl}$ solution after removing biofilms and corrosion products in the presence of SRB after 8 days of incubation: a $0 \mathrm{mT}$ MF; b $150 \mathrm{mT} \mathrm{MF}$

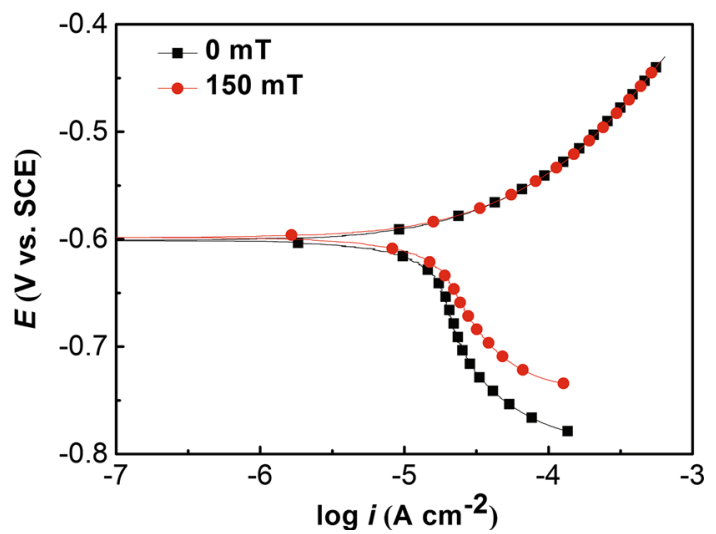

Fig. 3 Polarization curves of Q235 carbon steel in 3 wt\% $\mathrm{NaCl}$ solution in the presence of SRB after 8 days of incubation

MF accelerated SRB corrosion. This also kept consistency with the results of the polarization curve measurements.

\subsection{Corrosion of Q235 Steel in EPS-Containing Solution}

\subsubsection{Characterization of EPS}

In this work, UV and ATR-IR measurements were used to confirm the adsorption of EPS on carbon steel and the direct interaction between the EPS macromolecules and ferrous cations. The UV spectrum of the EPS is shown in Fig. $6 \mathrm{a}$, in which the significant absorbance between 260 and $280 \mathrm{~nm}$ was correspond to the presence of the DNA and proteins. Figure $6 \mathrm{~b}$ illustrates the Fourier-transformed infrared (FT-IR) and ATR-IR spectra of EPS adsorbed on carbon steel surface. Figure 6c shows the corresponding second-derivative transformation of the ATR-IR spectra in the range of $1700-1000 \mathrm{~cm}^{-1}$. The distinct peaks at 1640 and $1564 \mathrm{~cm}^{-1}$ were assigned to the amide $\mathrm{I}(\mathrm{C}=\mathrm{O}$ stretching) and amide II groups ( $\mathrm{N}-\mathrm{H}$ bending and $\mathrm{C}-\mathrm{N}$ stretching). Owing to the presence of carboxylic groups in proteins and carbohydrates, the peaks positioned at 1467 and $1418 \mathrm{~cm}^{-1}$ were dominated. The characteristic peak at $1300 \mathrm{~cm}^{-1}$ was indicative of amide III region of proteins ( $\mathrm{N}-\mathrm{H}$ in-plane bending coupled to the $\mathrm{C}-\mathrm{N}$ stretching; $\mathrm{C}-\mathrm{H}$ and $\mathrm{N}-\mathrm{H}$ deformation) [40].

The second-derivative transformation revealed that the peak at $1564 \mathrm{~cm}^{-1}$ for the EPS was fragmented into two signal peaks at 1560 and $1536 \mathrm{~cm}^{-1}$ for the adsorbed EPS on carbon steel surface (the red arrow). Generally, the appearance of new chemical bonds due to the change of functional groups can be responsible for the splitting and shift of the peaks. It could be concluded from the results that EPS could easily adsorb on the steel surface, thus influenced the corrosion process of steel [41]. And, the organic macromolecules in EPS played the key roles.

\subsubsection{Electrochemical Measurements}

The cyclic double-polarization curves of Q235 carbon steel under different corrosion conditions are shown in Fig. 7, which are performed to explore the effect of EPS and MF on the electrochemical behaviour of Q235 carbon steel.

Table 2 Fitted results of polarization curves in Fig. 3 with SRB in the absence and presence of SRB after 8 days of incubation in 3 wt $\%$ NaCl solution ( $E_{\text {corr }}$ : free corrosion potential; $b_{\mathrm{a}}$ and $b_{\mathrm{c}}$ correspond to the anodic and cathodic Tafel slopes, respectively)

\begin{tabular}{lllll}
\hline Static magnetic field $(\mathrm{mT})$ & $E_{\text {corr }}(\mathrm{mV})$ & $i_{\text {corr }}\left(\mathrm{mA} \mathrm{cm}^{-2}\right)$ & $b_{\mathrm{a}}\left(\mathrm{mV} \mathrm{dec}^{-1}\right)$ & $b_{\mathrm{c}}\left(\mathrm{mV} \mathrm{dec}^{-1}\right)$ \\
\hline 0 & -600 & 0.16 & 110 & -393 \\
150 & -598 & 0.20 & 111 & -204 \\
\hline
\end{tabular}




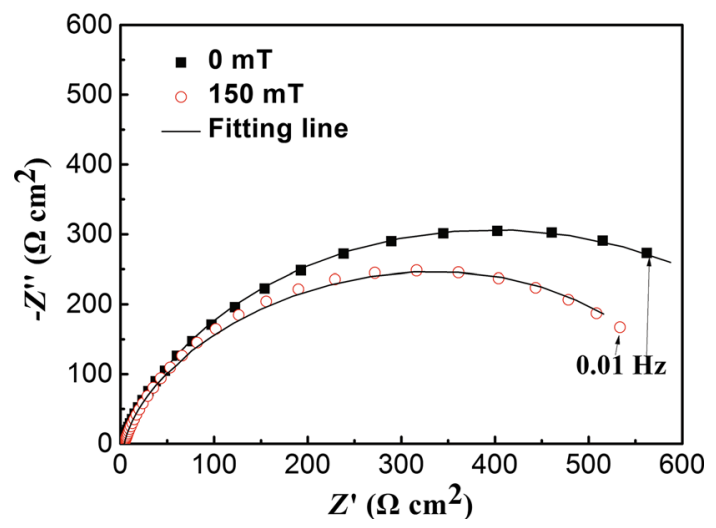

Fig. 4 Nyquist plots of coupons with SRB in the absence and presence of MF after 8 days of incubation in $3 \mathrm{wt} \% \mathrm{NaCl}$ solution ( $Z^{\prime}$ and $Z^{\prime \prime}$ are the real and imaginary parts, respectively)

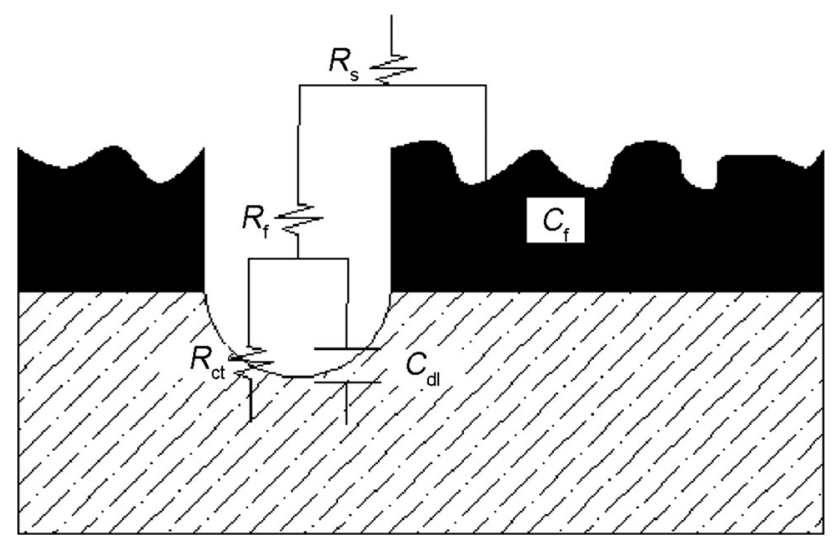

Fig. 5 Equivalent circuit used to fit EIS data $\left(R_{\mathrm{S}}\right.$ is the solution resistance, $R_{\mathrm{f}}$ and $C_{\mathrm{f}}$ the resistance and the capacitance of the biofilm, respectively. $R_{\mathrm{ct}}$ and $C_{\mathrm{dl}}$ correspond to a charge transfer resistance and a double layer capacitance, respectively)

Table 3 Fitted results of EIS data corresponding to Figs. 4 and 8 with SRB and EPS in the absence and presence of MF after 8 days of incubation in $3 \mathrm{wt} \% \mathrm{NaCl}$ solution

\begin{tabular}{lllllll}
\hline \multicolumn{5}{c}{$\mathrm{SRB}+\mathrm{MF}$} & \multicolumn{2}{l}{$\mathrm{EPS}+\mathrm{MF}$} \\
\hline & $0 \mathrm{mT}$ & $150 \mathrm{mT}$ & Blank & EPS & MF & EPS + MF \\
$R_{\mathrm{ct}}\left(\Omega \mathrm{cm}^{-2}\right)$ & 852 & 673 & 1200 & 1780 & 2050 & 430 \\
\hline
\end{tabular}

According to previous study, the shift in the corrosion potential revealed the concentration change of iron ions in the electrolyte due to the fractional oxidation of iron through anodic polarization [42]. In Fig. 7, coupon with EPS $(0.42 \mathrm{~V})$ exhibited larger $\Delta E$ than that of the control group $(0.37 \mathrm{~V})$. The enhancement of $\Delta E$ value was possibly associated with the complexation of the EPS with iron, which could cause enrichment of iron ions on the electrode surface. By the implementation of MF, the $\Delta E$ was further enhanced, signifying that the application of both MF and
EPS accelerated the formation of metal oxides. Iron with positive charge is difficult to leave electrode surface in the presence of MF, because magnetic induction lines are perpendicular to electrode surface. And, the iron ions with positive charge in bulk solution can also migrate to electrode surface. These will promote the formation of corrosion products. More importantly, the plateau in the anodic region in a potential range of -0.9 to $-0.45 \mathrm{~V}$ versus SCE could also be attributed to the increased dissolution rate of iron from the surface, which in turn assisted the formation of a corrosion product film [42].

In addition, the corrosion current density $\left(i_{\text {corr }}\right)$ was also obtained using Tafel extrapolation method, and the corresponding results are shown in Table 4. Either MF or EPS substantially inhibited steel corrosion in a $3 \mathrm{wt} \% \mathrm{NaCl}$ solution. However, the corrosion current density was $0.36 \mathrm{~mA} \mathrm{~cm}^{-2}$ in the presence of both MF and EPS, which was significantly larger compared with the other groups. These imply that the synergistic effect of MF and EPS tremendously accelerated steel corrosion in a $3 \mathrm{wt} \% \mathrm{NaCl}$ solution. Moreover, when the potential was $<-0.94 \mathrm{~V}$ versus SCE, in the magnified zone as shown in Fig. 7, the current density in the group with both MF and EPS continued to increase and was significantly higher than the others. These results also indicated that the interaction between MF and EPS could accelerate steel corrosion.

Furthermore, EIS results under different corrosion conditions are provided as shown in Fig. 8. All EIS data were fitted using the same equivalent circuit as shown in Fig. 5, where the parallel $R_{\mathrm{f}}$ and $C_{\mathrm{f}}$ indicated the resistance of the film. The corresponding fitted results of EIS data are listed in Table 3. The addition of EPS resulted in the increase of impedance and $R_{\mathrm{ct}}$ values, demonstrating that the EPS adsorbed on the electrode surface showed slightly protective effect against the steel corrosion. The application of MF without SRB also led to the increase of the $R_{\mathrm{ct}}$ values and therefore slowed down the steel corrosion. However, substantial decrease in the $R_{\mathrm{ct}}$ value was found in the presence of both MF and EPS, suggesting the synergistic effect of MF and EPS on the corrosion of carbon steel in a $3 \mathrm{wt} \% \mathrm{NaCl}$ solution. These results were in good agreement with the analysis results of polarization curves. Moreover, the Nyquist curves bent inwards at low frequencies, which could be explained by the adsorption/ desorption of EPS or the adsorbed intermediary species produced during the dissolution of iron [17].

\subsubsection{Surface Analysis}

SEM images of coupons after 8 days of incubation in testing solution containing EPS in the absence and presence of MF are shown in Fig. 9. Without applying MF, comparatively uniform thin corrosion product film could be 
(a)

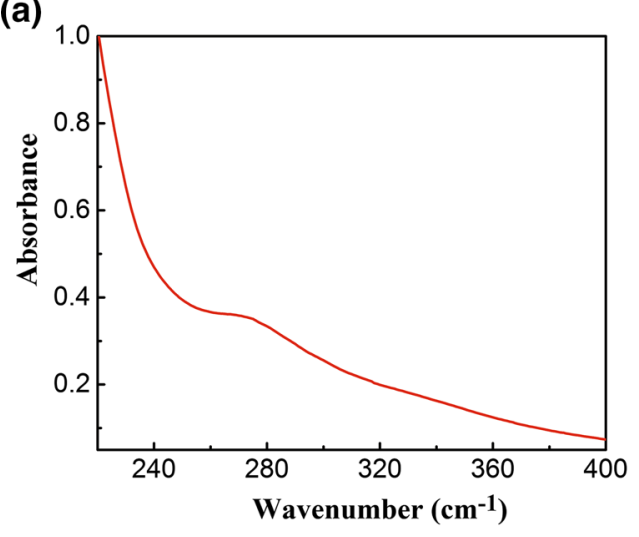

(b)

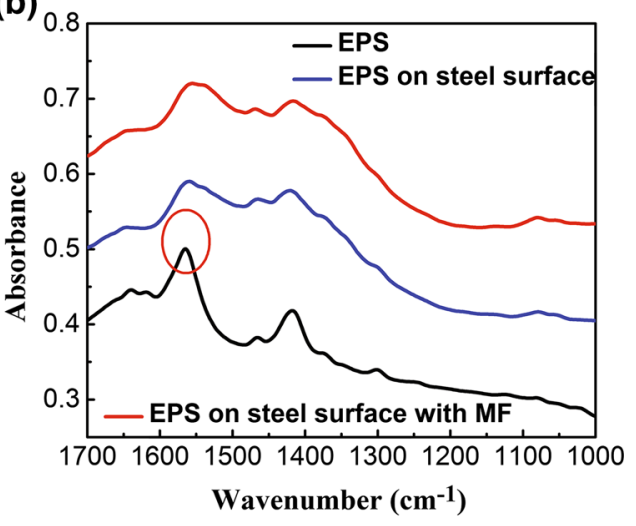

(c)

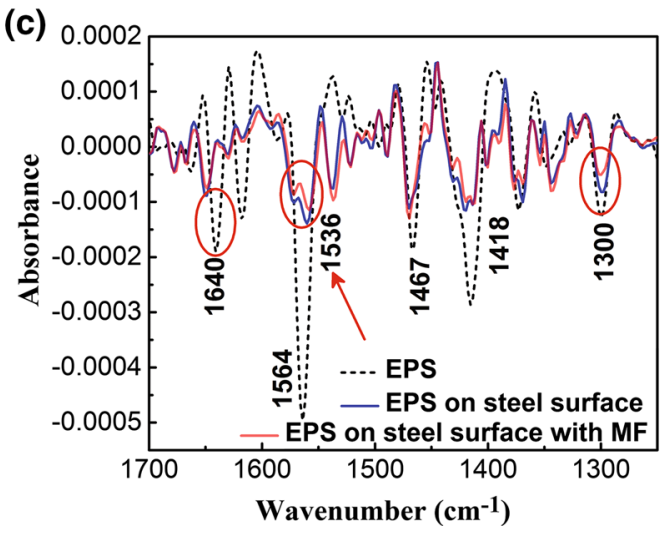

Fig. 6 UV spectrum of EPS extracted from SRB culture medium a, FT-IR spectra of EPS, EPS adsorbed on steel surface in the absence and presence of $150 \mathrm{mT} \mathrm{mF} \mathbf{b}$, and corresponding second-derivative transformations of IR spectra $\mathbf{c}$

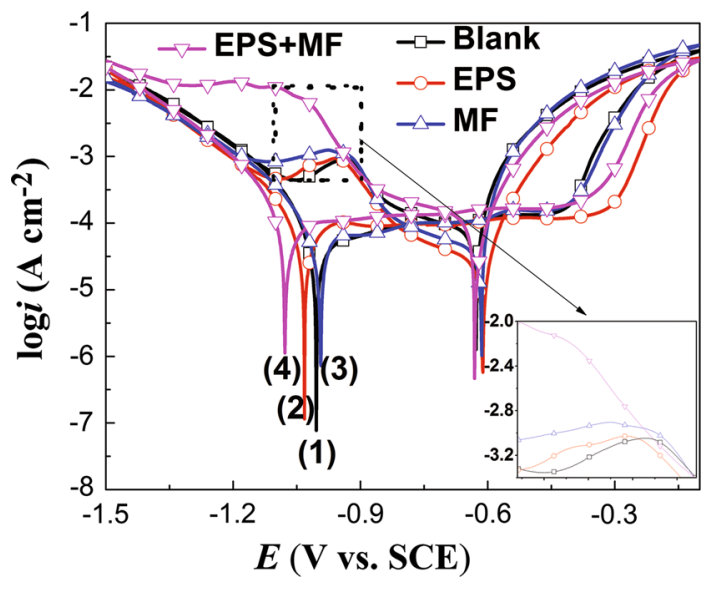

Fig. 7 Cyclic double-polarization curves of Q235 carbon steel under different corrosion conditions in $3 \mathrm{wt} \% \mathrm{NaCl}$ solution (the coupon without EPS and MF is as blank)

observed on the steel surface, and some polish lines also could be clearly observed (Fig. 9a, c). The presence of polish lines suggested a slight corrosion induced by EPS in the absence of MF. However, a large amount of corrosion products with some cracks could be clearly observed on the steel surface in the presence of MF (Fig. 9b, d),
Table 4 Fitted results of cyclic double-polarization curves in $3 \mathrm{wt} \%$ $\mathrm{NaCl}$ solution after 8 days of incubation under different corrosion conditions

\begin{tabular}{lll}
\hline Situation & $\Delta E_{\text {corr }}(\mathrm{V})$ & $i_{\text {corr }}\left(\mathrm{mA} \mathrm{cm}^{-2}\right)$ \\
\hline Blank & $0.37 \pm 0.01$ & 0.28 \\
EPS & $0.42 \pm 0.02$ & 0.19 \\
SMF & $0.38 \pm 0.01$ & 0.21 \\
EPS + SMF & $0.45 \pm 0.03$ & 0.36 \\
\hline
\end{tabular}

demonstrating that the presence of MF promoted the formation of corrosion products. The more corrosion products indicated the more irons dissolved from the steel matrix. So, the SEM images indirectly indicated that MF promoted the steel corrosion induced by EPS.

Additionally, elemental mapping of selected zone from Fig. 9c, d for the analysis of corrosion products was obtained by EDS, and the corresponding quantities of elements from the selected zone in Fig. 9c, $d$ are listed in Table 5. It was confirmed by the results that iron oxides and iron chloride were the major corrosion products. Compared with the carbon steel without MF, the 


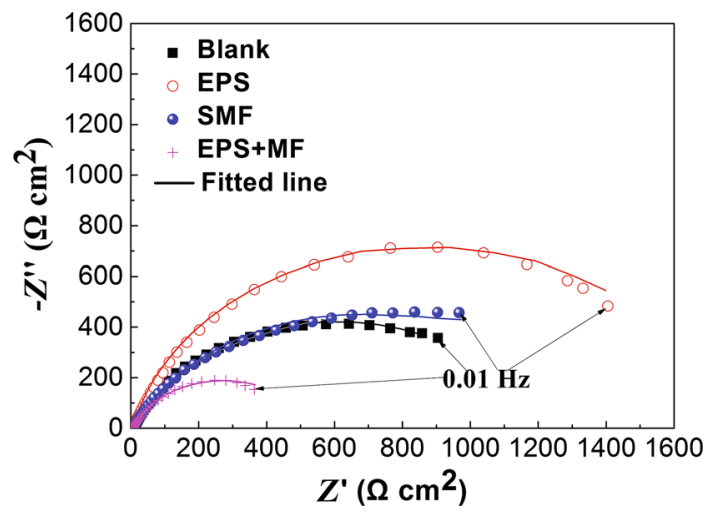

Fig. 8 Nyquist plots of coupons under different corrosion conditions after 8 days of incubation in $3 \mathrm{wt} \% \mathrm{NaCl}$ solution

percentage of chloride ions was higher for the coupon in the presence of MF (Table 5), which implied that MF resulted in the enrichment of chloride on the carbon steel surface. The metal surface could be stacked by EPS which was supposed to act as a barrier to aggressive ions such as chloride ions. However, MF assisted the transfer of the aggressive chloride ions, which consequently demolished
Table 5 EDS analysis results corresponding to SEM images in Fig. 9 in the absence and presence of MF in EPS-containing testing solution

\begin{tabular}{llcll}
\hline MF $(\mathrm{mT})$ & Situation & $\mathrm{O}(\mathrm{wt} \%)$ & $\mathrm{Cl}(\mathrm{wt} \%)$ & $\mathrm{Fe}(\mathrm{wt} \%)$ \\
\hline 0 & EPS & 6.63 & 0.72 & 70.06 \\
150 & EPS + MF & 26.96 & 7.91 & 44.37 \\
\hline
\end{tabular}

the protective film and therefore boosts up the corrosion rate of the Q235 steel in the presence of EPS and MF.

Because it has been previously reported that MF is liable to influence the orientation of the membrane protein crystals [43] and the thickness of protein solutions as well [44], this synergistic acceleration between MF and EPS can be related to the possibility that the adequate intensity of MF alters the orientation of the EPS, and the newly ordered arrangement of the EPS provides the respective channels for the diffusion of chloride ions and oxygen, as shown in Fig. 10. Thus, the corrosion of Q235 steel in a $\mathrm{NaCl}$ solution was significantly accelerated in the presence of both MF and EPS.
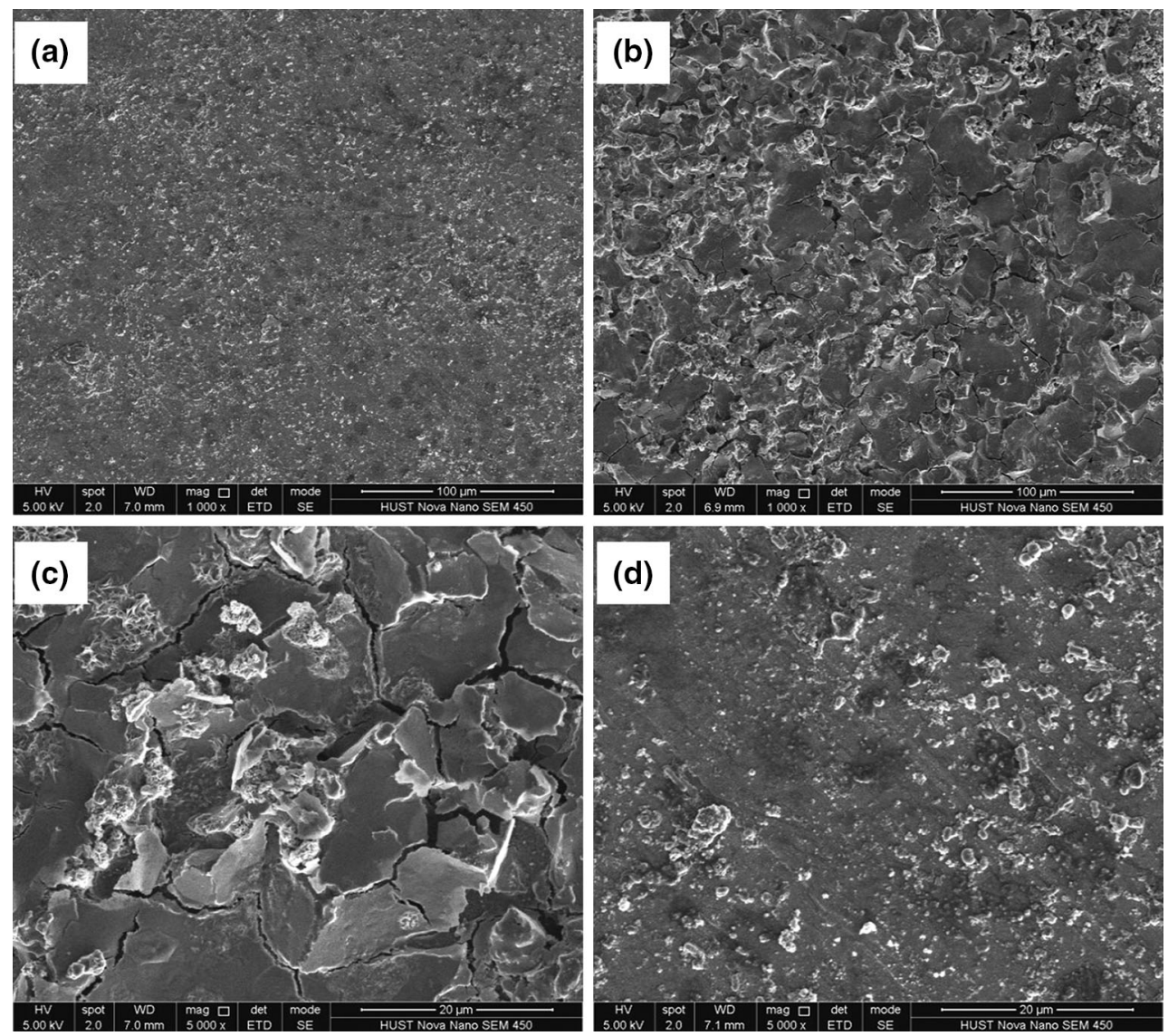

Fig. 9 SEM images of coupons under different corrosion conditions after 8 days of incubation in $3 \mathrm{wt} \% \mathrm{NaCl}$ solution containing EPS in the absence $\mathbf{a}, \mathbf{c}$ and presence $\mathbf{b}, \mathbf{d}$ of MF at low $\mathbf{a}, \mathbf{b}$ and high $\mathbf{c}, \mathbf{d}$ magnification 

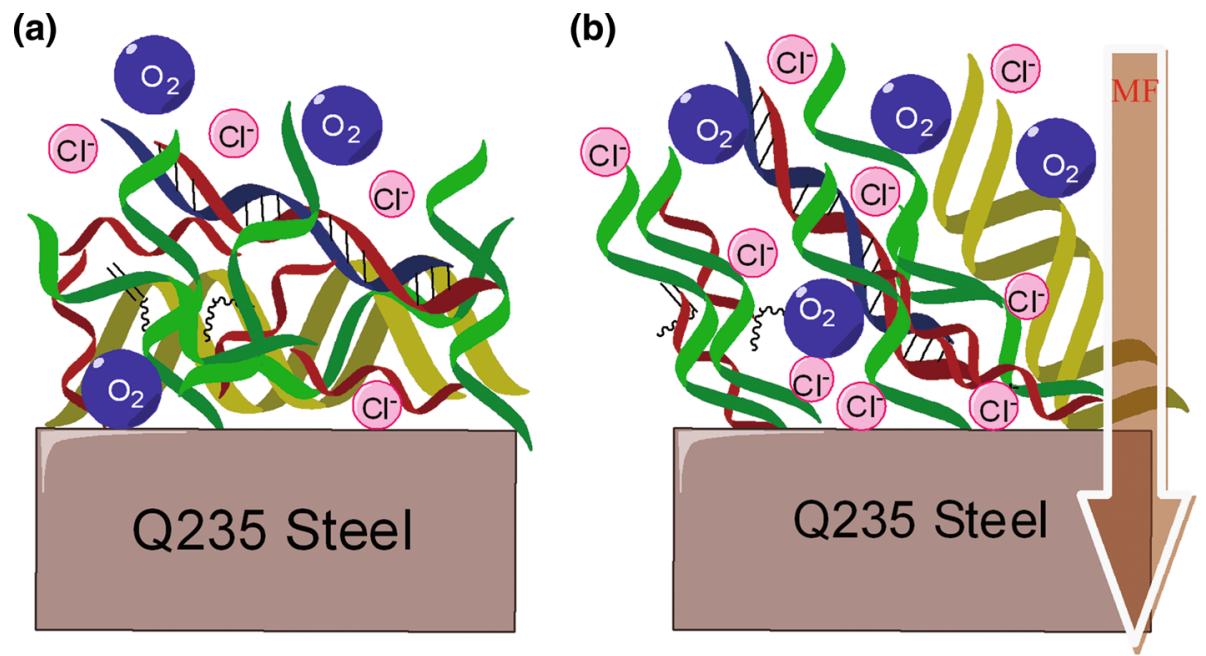

Fig. 10 Schematic diagram of EPS steel corrosion in EPS-containing testing solution in the absence a and presence $\mathbf{b}$ of MF

\section{Conclusion}

A $150 \mathrm{mT}$ MF could accelerate steel corrosion in a $3 \mathrm{wt} \%$ $\mathrm{NaCl}$ solution containing SRB by $202 \%$. Pitting corrosion was the major corrosion type of steel in this work. The analysis results of polarization curves indicated that MF influenced the diffusion of dissolved oxygen and chloride ions as well as the reduction process of oxygen. Both the adsorbed EPS on the steel surface and the direct interaction between EPS and iron ions were confirmed by ATR-IR measurements. Electrochemical analysis results indicated that either EPS or MF inhibited the corrosion of Q235 carbon steel, but the combination of MF and EPS significantly accelerated the corrosion of Q235 carbon steel.

Acknowledgements This work was financially supported by the Shenzhen Strategic Emerging Industry Development Special Fund Project (No. JCYJ20130401144744190) and the Innovation Foundation of Huazhong University of Science and Technology Innovation Institute (Nos. 2015TS150, 2015ZZGH010). We acknowledge the support of the Analytical and Testing Center of the Huazhong University of Science and Technology for SEM observation.

\section{References}

[1] F. Liu, J. Zhang, C. Sun, Z. Yu, B. Hou, Corros. Sci. 83, 375 (2014)

[2] X.T. Chang, Y.S. Yin, G.H. Niu, T. Liu, S. Cheng, S.B. Sun, Acta Metall. Sin. (Engl. Lett.) 20, 334 (2007)

[3] D. Xu, Y. Li, F. Song, T. Gu, Corros. Sci. 77, 385 (2013)

[4] D. Xu, T. Gu, Int. Biodeterior. Biodegrad. 91, 74 (2014)

[5] D. Cetin, M.L. Aksu, Corros. Sci. 51, 1584 (2009)

[6] M. Stipanicev, F. Turcu, L. Esnault, E.W. Schweitzer, R. Kilian, R. Basseguy, Electrochim. Acta 113, 390 (2013)

[7] B. Zheng, Y. Zhao, W. Xue, H. Liu, Surf. Coat. Technol. 216, $100(2013)$

[8] T.Q. Wu, M.C. Yan, D.C. Zeng, J. Xu, C.K. Yu, C. Sun, W. Ke, Acta Metall. Sin. (Engl. Lett.) 28, 93 (2015)
[9] X.B. Shi, W. Yan, M.C. Yan, W. Wang, Z.G. Yang, Y.Y. Shan, K. Yang, Acta Metall. Sin. (Engl. Lett.) 30, 601 (2017)

[10] V. Somasundaram, L. Philip, S.M. Bhallamudi, Chem. Eng. J. 171, 572 (2011)

[11] M.D. Ghafari, A. Bahrami, I. Rasooli, D. Arabian, F. Ghafari, Int. Biodeterior. Biodegrad. 80, 29 (2013)

[12] R. Stadler, W. Fuerbeth, K. Harneit, M. Grooters, M. Woellbrink, W. Sand, Electrochim. Acta 54, 91 (2008)

[13] A.F.F. Giacobone, S.A. Rodriguez, A.L. Burkart, R.A. Pizarro, Int. Biodeterior. Biodegrad. 65, 1161 (2011)

[14] W.B. Beech, J. Sunner, Curr. Opin. Biotechnol. 15, 181 (2004)

[15] H. Liu, H.H.P. Fang, Biotechnol. Bioeng. 80, 806 (2002)

[16] J.T. Jin, G.X. Wu, Z.H. Zhang, Y.T. Guan, Bioresour. Technol. 165, 162 (2014)

[17] Q. Bao, D. Zhang, D.D. Lv, P. Wang, Corros. Sci. 65, 405 (2012)

[18] J. Jajte, J. Grzegorczyk, M. Zmyslony, E. Rajkowska, Bioelectrochemistry 57, 107 (2002)

[19] R.R. Mohammed, M.R. Ketabchi, G. McKay, Chem. Eng. J. 243, 31 (2014)

[20] C. Niu, J.J. Geng, H.Q. Ren, L.L. Ding, K. Xu, W.H. Liang, Bioresour. Technol. 150, 156 (2013)

[21] J. Hu, C.F. Dong, X.G. Li, K. Xiao, J. Mater. Sci. Technol. 26, $355(2010)$

[22] Z.P. Lu, W. Yang, Corros. Sci. 50, 510 (2008)

[23] A. Rucinskiene, G. Bikulcius, L. Gudaviciute, E. Juzeliunas, Electrochem. Commun. 4, 86 (2002)

[24] R. Sueptitz, K. Tschulik, M. Uhlemann, L. Schultz, A. Gebert, Corros. Sci. 53, 3222 (2011)

[25] R. Sueptitz, K. Tschulik, M. Uhlemann, L. Schultz, A. Gebert, Electrochim. Acta 56, 5866 (2011)

[26] F. Al-Abbas, A. Kakpovbia, B. Mishra, D. Olson, J. Spear, Could non-destructive methodologies enhance the microbiologically influenced corrosion (MIC) in pipeline systems?, in The 39th Annual Review of Progress in Quantitative Nondestructive Evaluation (AIP Publishing, 2013), p. 1270

[27] J. Filipic, B. Kraigher, B. Tepus, V. Kokol, I. Mandic-Mulec, Bioresour. Technol. 120, 225 (2012)

[28] L. Fojt, L. Strasak, V. Vetterl, J. Smarda, Bioelectrochemistry 63, 337 (2004)

[29] W.J. Ji, H.M. Huang, A.H. Deng, C.Y. Pan, Micron 40, 894 (2009)

[30] J. Novak, L. Strasak, L. Fojt, I. Slaninova, V. Vetterl, Bioelectrochemistry 70, 115 (2007) 
[31] B.J. Zheng, K.J. Li, H.F. Liu, T.Y. Gu, Ind. Eng. Chem. Res. 53, 48 (2014)

[32] A. Bahaj, I. Beech, S. Campbell, P. James, F. Walsh, The effect of magnetic fields on biofilm formation by sulphate reducing bacteria and its implications in the corrosion of iron and steel, in US National Science Foundation Workshop on Biocorrosion and Biofouling, 12 May 1992

[33] H. Liu, C. Fu, T. Gu, G. Zhang, Y. Lv, H. Wang, H. Liu, Corros. Sci. 100, 484 (2015)

[34] Z.H. Dong, T. Liu, H.F. Liu, Biofouling 27, 487 (2011)

[35] H. Liu, T. Gu, Y. Lv, M. Asif, F. Xiong, G. Zhang, H. Liu, Corros. Sci. 117, 24 (2017)

[36] Z.H. Dong, W. Shi, H.M. Ruan, G.A. Zhang, Corros. Sci. 53, 2978 (2011)
[37] L. Yu, J. Duan, X. Du, Y. Huang, B. Hou, Electrochem. Commun. 26, 101 (2013)

[38] H. Liu, T. Gu, G. Zhang, Y. Cheng, H. Wang, H. Liu, Corros. Sci. 102, 93 (2016)

[39] H. Liu, D. Xu, A.Q. Dao, G. Zhang, Y. Lv, H. Liu, Corros. Sci. 101, 84 (2015)

[40] A. Omoike, J. Chorover, Biomacromolecules 5, 1219 (2004)

[41] V. Crupi, R. Ficarra, M. Guardo, D. Majolino, R. Stancanelli, V. Venuti, J. Pharm. Biomed. Anal. 44, 110 (2007)

[42] P. Smith, S. Roy, D. Swailes, S. Maxwell, D. Page, J. Lawson, Chem. Eng. Sci. 66, 5775 (2011)

[43] N. Numoto, K. Shimizu, K. Matsumoto, K. Miki, A. Kita, J. Cryst. Growth 367, 53 (2013)

[44] C.W. Zhong, N.I. Wakayama, J. Cryst. Growth 226, 327 (2001) 